\title{
Sinalizações sobre a escolarização de alunos surdos: alguns estudos e problematizações
}

\author{
Signs about the schooling of deaf students: some studies and \\ problematizations
}

\author{
Silvana Matos Uhmann (silvana_uhmann@id.uff.br) \\ Instituto de Educação de Angra dos Reis (Iear) da Universidade Federal Fluminense (UFF) \\ Maria Simone Vione Schwengber (simone@unijui.edu.br) \\ Universidade Regional do Noroeste do Estado do Rio Grande do Sul (Unijuí)
}

\begin{abstract}
Resumo: Este texto apresenta reflexões sobre a escolarização de alunos surdos, sobretudo diante do acesso e permanência destes sujeitos nos espaços escolares brasileiros. Sob a perspectiva bibliográfica e em caráter qualitativo, foram realizadas buscas nos Periódicos da CAPES e Banco de Teses e Dissertações no ano de 2018, sendo encontrados alguns estudos que discutem a temática e que nos fazem debruçar sobre o seguinte questionamento: $\mathrm{O}$ que a produção acadêmica tem a dizer sobre $\mathrm{o}$ acesso e permanência de alunos surdos em escolas regulares? São problematizados alguns dos limites ainda existentes na inclusão de alunos surdos (valorização da audição, estratégias de correção/reabilitação da surdez, tendência à homogeneidade, entre outros), bem como realçada a importância do reconhecimento e legitimação da singularidade e diferença dos alunos surdos como possibilidade de qualificação não apenas do acesso (já garantido legalmente), mas também para a significativa permanência desses alunos nos espaços escolares.
\end{abstract}

Palavras-chave: Inclusão de alunos surdos; LIBRAS; Estudo de Revisão.

Abstract: This text presents reflections on the schooling of deaf students, especially in view of the access and permanence of these subjects in Brazilian school spaces. From a bibliographic and qualitative perspective, searches were carried out in CAPES Journals and the Bank of Theses and Dissertations in 2018, with some studies that discuss the theme and that make us dwell on the following question: What academic production have to say about the access and permanence of deaf students in regular schools? Some of the limits that still exist in the inclusion of deaf students are questioned (valuing hearing, deafness correction / rehabilitation strategies, tendency to homogeneity, among others), as well as emphasizing the importance of recognizing and legitimizing the singularity and difference of deaf students as possibility of qualifying not only access (already legally guaranteed), but also for the significant permanence of these students in school spaces.

Keywords: Inclusion of deaf students; LIBRAS; Review Estudy. 


\section{IDEIAS E PROBLEMATIZAÇÕES INICIAIS}

A escola é um lugar repleto de sinalizações ${ }^{1}$ : múltiplas e infinitas. Sinais sobre as trajetórias, as histórias, vivências, práticas e subjetivações que retratam o processo de inclusão acontecendo na escola. A partir da perspectiva de processo, a escolarização e, aqui em especial a escolarização de alunos surdos, demonstra caminhos nada definidos, mas acontecem e/ou se modificam à medida que cada escola/sujeito estabelece alternativas/vivências singulares (UHMANN, 2018).

Tais sinalizações concedem centralidade à diferença constitutiva dos espaços escolares, que muitas vezes podem demonstrar ser interesse da mesmidade ${ }^{2}$ e da a necessidade de "fazer do outro o mesmo de mim" (SKLIAR, 2003, p. 3). É possível mexer diretamente nas relações de alteridade $^{3}$, especialmente em meio a práticas educativas que, mesmo diante da afirmação da diferença, por diversas vezes se confundiam com a 'confortável' alteridade do Mesmo. Essa é a escola que muitos sinalizam, uma escola nem melhor, nem pior, mas a escola da Contemporaneidade ${ }^{4}$ em meio às suas estratégias e artimanhas pensadas/organizadas para o acesso e permanência dos alunos.

O interesse pela temática da diferença na escola é pautado no reconhecimento de que alguns sujeitos e suas características são considerados 'mais visíveis' e nunca despercebidos, levam o título de 'mais diferentes' do que outros, sendo muitas vezes carregados, como bem destaca Skliar (2003), de estereótipos ${ }^{5}$ e $^{\text {preconceitos }}{ }^{6}$, os quais

\footnotetext{
1 'Sinalizações' será no decorrer desta escrita utilizada como metáfora para identificar e problematizar importantes aspectos a serem considerados sobre a escolarização de alunos surdos.

${ }^{2} \mathrm{O}$ que possibilita pensar como pano de fundo a padronização da conjuntura contemporânea em que cada vez mais são observados e enquadrados os obesos, pobres, homossexuais, pessoas com deficiência e tantas outras marcas que fogem de determinadas normalizações preestabelecidas.

${ }^{3}$ Expressa a qualidade ou estado do que é outro ou do que é diferente. A alteridade pode ser entendida como "a condição daquilo que é diferente de mim; a condição de ser o outro" (SILVA, 2000, p. 16)

${ }^{4}$ Contemporaneidade aqui entendida próxima das ideias da Modernidade que, conforme Castro (2009, p. 301), refere-se a "época de um poder que se exerce como disciplina sobre os indivíduos e como biopolítica sobre as populações”. Nesse cenário, a escola pode ser considerada uma invenção da Modernidade preocupada em controlar e disciplinar os sujeitos segundo suas definições.

${ }^{5}$ Estereótipo é aqui entendido como imagem preconcebida para definir pessoas ou situações; são como impressões, preconceitos e "rótulos" organizados de maneira generalizada, muitas vezes com teor preconceituoso e padronizando diversos aspectos relacionados ao ser humano e às suas ações.

${ }^{6}$ Compreendido por meio do pré-julgamento - literalmente, "pré-conceito" -, uma concepção que já existe sem que haja, por exemplo, fundamentação científica para tal. Por isso, o preconceito por vezes sustenta a intolerância ou o repúdio ao que não é aceito.
} 
sinalizam, por exemplo, para corpos sem um membro ou com comportamentos atípicos. Sinalizações que problematizam a escola a partir da norma, da normalidade, do esperado que, junto, trazem os estranhamentos, as omissões, os afastamentos e as práticas pedagógicas para o que frequentemente é considerado 'diferente', pois não cabe em uma regra definida, em um padrão de comportamento ou em modelos únicos de experiências escolares.

Ao considerarmos essas questões, o acesso e permanência dos alunos nas escolas brasileiras permanece em constante problemática, já que conforme Silva (2002, p. 66), a diferença "não pede tolerância, respeito ou boa vontade", mas, "desrespeitosamente, simplesmente difere". Ela é embaraçosa, incômoda, capaz de desestruturar a organização prévia da escola e suas escolhas, pondo-nos 'frente a frente' com um Outro que não conseguimos previamente identificar. Vai exigir novas perspectivas, muitas reflexões, mudanças de estratégias, atividades, recursos. A diferença na escola - a diferença dos surdos - passa longe de ser uma questão resolvida, mas é algo que demonstra múltiplas sinalizações que merecem ser problematizadas.

Neste intuito, sob a perspectiva bibliográfica e em caráter qualitativo (LÜDKE; ANDRÉ, 1986) foram realizadas buscas nos Periódicos da CAPES e Banco de Teses e Dissertações no ano de 2018, com os descritores "Surdos", "inclusão" e "diferença" (conceitos de interesse e escolha das autoras); foram selecionados os estudos que continham algum destes descritores no título do trabalho. Após, buscou-se “[...] organizar os dados, num processo de inúmeras leituras e releituras" (LÜDKE; ANDRÉ, 1986, p.42) e, ao "tentar detectar temas e temáticas mais frequentes" (Ibidem), debruçou-se sobre o seguinte questionamento: O que a produção acadêmica tem a dizer sobre o acesso e permanência de alunos surdos em escolas regulares?

\section{O QUE JÁ DIZEM ALGUMAS PESQUISAS}

A Educação de Surdos vem ganhando visibilidade nas pesquisas educacionais, em um processo oposto ao de muitos anos em que os campos de saber definiam "verdades" hegemônicas sobre os surdos pouco ou quase nada contestáveis. Não mais se trata de uma visibilidade restrita à trajetória histórica de exclusão e às suas 
justificativas para assim permanecer, mas de visibilidade do direito de ter direitos - do direito à diferença. Se anteriormente a surdez era exclusivamente sinônimo de anormalidade, agora é possível refletir sobre ela indo além da busca por sujeitos hegemônicos, da norma historicamente firmada e de contextos rígidos, fixos e predefinidos.

Ao realizar a busca nos periódicos da CAPES foi possível perceber a importância de reflexões sobre a surdez como diferença linguística e a necessidade de mais estudos que aprofundem o tema - pois, mesmo sem demarcar período/ano para a busca, foram encontrados apenas seis artigos ${ }^{7}$. Sobre algumas dessas pesquisas, é relevante destacar: a cultura surda como resultado da construção de uma nova forma de representação do Outro, sob o prisma da diferença, importando a apropriação de conceitos como os de identidade, diferença e cultura a partir de uma perspectiva política e de legitimidade (PATROCÍNIO, 2017).

Sua inclusão necessita ser constantemente problematizada, uma vez que a legislação existente (BRASIL, 2008) não é garantia para a qualidade de escolarização desses sujeitos. Pelo contrário, estudos como os de Martins (2006) nos mostram como ainda é possível pontuar situações geradoras de 'invisibilidade' dos surdos - “sensação de apagamento" do outro, de forma intencional ou sutil e discreta diante do processo de inclusão, em que a não aceitação da diferença se configura em uma problemática muito observada.

Essa problemática nos aproxima do questionamento proposto por Sampaio (2010): como pensar uma escola que, de fato, reconheça as singularidades linguísticas e culturais dos alunos e alunas? Trata-se de uma reflexão sem um fim definido, mas que

\footnotetext{
${ }^{7}$ São eles: "Estudos culturais, diferença e surdez: uma leitura teórica" de autoria de Paulo Roberto Tonani Patrocínio; "Discursos sobre a surdez: deficiência, diferença, singularidade e construção de sentido" de autoria de Cláudia Bisol e Tania Mara Sperb; "O que me torna invisível? A psicanálise como ferramenta para entender o 'apagamento' das diferenças na inclusão escolar de surdos” de autoria de Vanessa Regina de Oliveira Martins; "A presença de uma aluna surda em uma turma de ouvintes - possibilidade de (re)pensar a mesmidade e a diferença no cotidiano escolar" de autoria de Carmen Sanches Sampaio; "O eu e o outro no campo discursivo da surdez" de autoria de Maria Clara Maciel de Araújo Ribeiro e Glaucia Muniz Proença Lara; "Pedagogia surda e bilinguismo: pontos e contrapontos na perspectiva de uma educação inclusiva" de autoria de Eliziane Manosso Streiechen, Cibele Krause-Lemke, Jáima Pinheiro de Oliveira e Gilmar de Carvalho Cruz.
} 
demonstra acontecer em meio ao respeito à perspectiva da diferença. Ribeiro e Lara (2010) voltam seu olhar para os discursos dos próprios surdos que convidam a refletir com cautela a constante associação da surdez à deficiência e anormalidade, uma vez que os surdos lutam politicamente pela aceitação de sua singularidade e legitimação.

Na busca realizada no Banco de Dados de Teses e Dissertações da CAPES, encontramos pesquisas que igualmente tratam da surdez como diferença linguística. Foram encontrados 30 estudos $^{8}$ - igualmente sem demarcação de período/ano para a busca - que, abordando a escolarização de surdos, apresentaram perspectivas e/ou

${ }^{8}$ São eles: "Processos de construção e desenvolvimento de currículo para surdos com deficiência em uma escola bilíngue para surdos" de autoria de Cássia Lobato Martins; "Cultura e identidade surda no discurso curricular e seus efeitos na docência de professores formados no curso de letras/libras-polo UFMS" de autoria de Cláudia de Arruda Sarturi; "Vivemos um ser desconjuntado - A produção da diferença nos discursos dos surdos acadêmico" de autoria de Violeta Porto Moraes; "Os currículos de formação de professores para surdos na UFSM: a educação especial como campo de saber" de autoria de Vera Lúcia Marostega; "O desafio do bilinguismo para alunos surdos no contexto da inclusão: o caso de uma escola Municipal do Rio de janeiro" de autoria de Adriana Ramos Silva; "Escolarização de surdos no ensino médio em natal/RN: vendo e ouvindo vozes" de autoria de Pedro Luiz dos Santos Filho; "A diferença e as rasuras do ensino inclusivo: Aproximações e distanciamento entre o atendimento educacional especializado realizados com alunos surdos e o acontecimento de Deleuze" de autoria de Eliane de Souza Ramos; "Escola bilíngue para surdos: constituição de práticas que configuram um espaço bilíngue" de autoria de Andréa Hees Drumond; "Percursos de escolarização de acadêmicos surdos no ensino superior" de autoria de Jaqueline Reni Loss; "Educação e constituição do sujeito surdo: discurso que circulam na ANPED no período de 1990 a 2010" de autoria de Cinara Franco Barberena; "Surdos "incluídos" sujeitos ou assujeitados" de autoria de Wander Luís Matias; "Emergência dos estudos surdos em educação no Brasil" de autoria de Luciane Breciane Lopes; "Discursos sobre pedagogias surdas" de autoria de Danieli de Paula Formozo; "Interações da criança surda em escola surda" de autoria de Elenara Borges Silveira Franzoi; "Discursos sobre a inclusão escolar: governamento docente e normalização dos sujeitos surdos pelo atendimento educacional especializados" de autoria de Ana Claudia Ramos Cardoso; "Políticas educacionais de inclusão: a escolarização de surdos em Uberlândia/MG" de autoria de Lucio Cruz Silveira Amorim; "A prática docente na inclusão educacional de um aluno surdo com implante coclear" de autoria de Juliana Pêgas Costa; "Educação de surdos: o contexto escolar e a perspectiva bilíngue" de autoria de Scheila Tatiane dos Santos Fucks; "Inclusão do aluno surdo no ensino médio" de autoria de Ademar Miller Junior; "As artes de governar no contexto da educação de surdos: estratégias de governamento da escola inclusiva" de autoria de Juliana Cesimbra-Conrado; "Educação bilíngue: discurso que produzem a educação de surdos no brasil" de autoria de Ingrid Ertel Stürmer; "Limites e possibilidades da educação bilíngue para surdos no contexto das políticas de inclusão (1990-2007): implicações à formação de professores" de autoria de Silvana Elisa de Morais Schubert; "A emergência das políticas de educação bilíngue para surdo no brasil na racionalidade" de autoria de Mônica Zavacki de Morais; "Narrativas de professoras ouvintes em contextos de ensino bilíngue em salas específicas para surdos: o que contam sobre a (re) construção do trabalho e da identidade docente?" de autoria de Jessie Ortiz Marimon; "Inter-relações surdos e ouvintes no processo de apropriação do conhecimento escolar por estudantes surdos" de autoria de Tamille Correia de Miranda Milanezi; "Possíveis negociações dos discursos curriculares no contexto da educação bilíngue de uma escola de surdos do Rio Grande do Sul" de autoria de Marcele Martinez Caceres; "Formação docente para a atuação com estudantes surdos" de autoria de Anderson Luchese; "A constituição de surdos em alunos no contexto escolar: conflitos, contradições e exclusões" de autoria de Márcia Barreto de Abreu; "Educação bilíngue para surdos: reflexões a partir de uma experiência pedagógica" de autoria de Claudia Regina Vieira; "O ensino da matemática para alunos surdos bilíngues: uma análise a partir das teorizações de Michel Foucault e Ludwing Wittgenstein" de autoria de Fernando Henrique Fogaça Carneiro. 
ênfases distintas. Sobre algumas dessas pesquisas, é relevante destacar primeiramente o que Morais (2015) buscou compreender: as estratégias que as políticas de educação bilíngue para surdos vêm exercendo na atualidade educacional/inclusiva nos coloca à frente de um cenário de conquistas, mas também de muitos desafios. Isso porque as políticas educacionais inclusivas vêm investindo em estratégias de condução dos alunos surdos na escola inclusiva, necessitando estes serem dóceis e produtivos, além de corresponderem às expectativas da normalidade (CONRRADO, 2014). Os estudos de Matias (2015) também destacam a escolarização dos surdos com possibilidades de torná-los assujeitados, e não sujeitos, pois a educação cada vez mais se mostra sob um caráter assistencialista ao receber a diferença e ao preocupar-se com o gerenciamento de suas experiências. Trata-se do investimento em sujeitos disciplinados no sistema regular e/ou especial como uma forma de regulação dos alunos na escola, sendo possível problematizar muitas áreas e práticas a partir do monolinguismo para surdos (CARNEIRO, 2017).

Estas ideias coadunam com os estudos de Silva (2015), os quis buscaram compreender por que alunos surdos não conseguem alcançar resultados escolares satisfatórios, destacando a ausência da língua primária/natural dos surdos como problemática principal. A fim de exemplificar, poderíamos citar também a insuficiência de intérpretes nos espaços escolares e de interação entre alunos surdos e professores, descritos nos estudos de Filho (2015), que não acontecem apenas em escolas regulares, mas estendem-se para outros espaços sociais, como pesquisado por Loss (2015) problematizando vivências de exclusões e falta de pertencimento no espaço do ensino superior a partir da retrospectiva de vida escolar de universitários surdos, sendo possível perceber que muitos alunos ainda encontram dificuldades de acessibilidade e permanência no Ensino Superior.

A Libras é secundarizada na escola e utilizada apenas entre surdos e/ou surdos/intérpretes, ocasionando dificuldades na comunicação, na socialização e, consequentemente, na proposta de inclusão dos alunos surdos. Abreu (2016) problematiza a constituição do aluno surdo, a comunicação pela língua de sinais e a pouca efetivação da proposta bilíngue a subjetivar sujeitos e a conduzi-los a lugares segregados na escola. Trata-se do registro de experiências negativas em que a diferença 
linguística dos surdos não é legitimada e o processo de inclusão encontra limites, como limitada interação entre surdos e ouvintes, relações conflituosas com professores e inexistência de significativas formações docentes.

Os estudos de Amorim (2015) analisam o processo de escolarização dos alunos surdos a partir de aspectos negativos diante da formação dos professores e a organização curricular, pouco preocupadas e engajados em contemplar a diferença linguística e cultural dos surdos. Marostega (2015) analisou os currículos de formação de professores para alunos surdos. Esta autora salienta que o conceito de diversidade (e não diferença) está articulado ao discurso de Educação Especial e, como consequência, encontra-se uma confusão conceitual e de entendimento sobre os surdos e as práticas pedagógicas a eles destinadas, o que também se reflete na forma como esses sujeitos podem ser subjetivados.

Com isso, é importante instigar questionamentos sobre a permanência de práticas de insucesso dos alunos e o apontamento de que é importante a formação docente estar à frente das abordagens educacionais destinadas aos alunos e, de maneira crítica, promover/contribuir com a aprendizagem e o desenvolvimento dos alunos (LUCHESE, 2016). Isto mostra-se possível mediante o respeito à diferença linguística dos surdos - também problematizada nos estudos de Stürmere (2015). Mas, como a diferença linguística dos surdos pode ser respeitada?

Lopes (2017) apresenta a importância da investigação sobre questões linguísticas, identidades culturais e educacionais que envolvem estes sujeitos, bem como a urgência de investigações que apontem para o rompimento de diagnósticos clínicos destinados aos surdos e à surdez. Costa (2015), também destaca a importância da identidade bilíngue conferida à pessoa surda e ao seu desenvolvimento linguístico/cultural, garantindo-a acesso à sua língua, identidade e cultura - sobretudo diante de sua escolarização, como reforça os estudos de Schubert (2017) a partir do necessário pertencimento da Libras (Língua Brasileira de Sinais) e da cultura dos surdos em todas as vivências escolares. Tais ideias reforçam a importância de uma política bilíngue, investindo na necessidade da língua de sinais e de um currículo com disciplinas específicas sobre cultura, história e identidade surda (CACERES, 2016). 
Trata-se de reconhecer a importância da Libras na escolarização de alunos surdos - não apenas na forma metodológica ao propiciar o diálogo/comunicação, mas também no nível conceitual e identitário para estes sujeitos. Estas ideias corroboram com os estudos de Vieira (2017), os quais definem a Libras como importante para a comunicação e o empoderamento da identidade surda, sendo utilizada não só para comunicação e interação, como também para aprendizagem, compreensão e condução da inclusão na escola - que, necessariamente, tem a ver com as condições de acesso e também de permanência dos alunos surdos.

\section{A ESCOLARIZAÇÃO DE ALUNOS SURDOS SOB SINALIZAÇÕES: A PROBLEMÁTICA DO ACESSO E DA PERMANÊNCIA}

Ao refletir sobre a inclusão de alunos surdos em escolas regulares, é importante reconhecer situações desiguais na escolarização ${ }^{9}$ ainda existentes que, além de restrições no acesso aos conhecimentos escolares, parece também ser condição para o desenvolvimento de relações desiguais estabelecidas dentro da escola - e que fora da escola, se diluem nas relações sociais mais amplas. Com frequência, a ausência de um braço, a necessidade de utilização de cadeira de rodas, a comunicação em Libras ${ }^{10}$, entre outras marcas ${ }^{11}$ que parecem expressamente personificar o "diferente", condicionam os alunos a representações que os inferiorizam em nome de uma normalidades ${ }^{12}$ que pouco concede espaço para o reconhecimento da diferença espontaneamente como ela é, principalmente para aquela que visivelmente se mostra. Rigo (2018, p.3) complementa a reflexão:

No contexto atual, a inclusão escolar tornou-se uma máxima inquestionável e, por isso, os sistemas de ensino tencionam as escolas a envolverem seus professores, de tal forma, que é quase impossível se opor a ela. Vive-se sob os efeitos de um poder/saber que, pelo convencimento, captura as pessoas,

\footnotetext{
${ }^{9}$ Escolarização é definida nesta pesquisa como uma prática social complexa efetivada entre sujeitos professor e aluno - por meio do processo formal de ensinar e aprender na constituição do conhecimento em espaço escolar, ou ainda, ação de ensino que resulta na aprendizagem, possivelmente ligada à ensinagem (relação entre ensino-aprendizagem), e não apenas à aprendizagem propriamente dita (ANASTASIOU, 2006).

${ }^{10}$ Libras: reconhecida oficialmente como Língua Brasileira de Sinais pela Lei n ${ }^{\circ} 10.436$ no ano de 2002.

${ }^{11}$ Marcas que podem ser discursivas e não discursivas que se inscrevem nos sujeitos e lhes concedem um lugar específico e restrito a essa marca, identidade, diferença.

12 Normas que correspondem aos padrões e expectativas do que é aceito e considerado regra, ou seja, qualquer aspecto "desviante" dos padrões estabelecidos pode ser considerado anormal.
} 
envolvendo-as em discursos morais e éticos para que lutem, insistentemente, por práticas que incluam (...).

Contudo, estas vivências nem sempre correspondem as especificidades dos alunos, bem como contribuem, de fato, com sua aprendizagem e desenvolvimento. Ao refletir sobre essas questões, nos deparamos com pesquisas como as de Angelucci; Luz (2010), Lacerda (2006) e Quadros (2003), as quais demonstram a escolarização de alunos surdos acontecendo por meio da comunicação em língua de sinais na sala de aula, mas questões atitudinais, culturais e curriculares que considerem a diferença linguística desses sujeitos ainda pouco reconhecidas, o que pode produzir um grande número de repetências, isolamento e evasão escolar desses alunos. Mesmo sob proposta a inclusiva (BRASIL, 2008) e com o aumento de matrículas de alunos surdos em escolas regulares, as pesquisas dos autores acima apontam o aumento no acesso desses alunos ao sistema regular, no entanto, demonstrando menores possibilidades educativas ao permanecerem nesse sistema. Neste caso, ao que parece, os limites iniciam à medida que a diferença se torna personificada em mãos que se comunicam, em detrimento do uso da majoritária língua oral.

Muitas vezes, o contexto escolar é descrito através de uma conduta classificatória, com o objetivo de averiguar aqueles a quem ele pode conceder lugares centrais e aqueles que, mediante discursos e práticas, serão distribuídos em suas margens. Afinal, como reconhecer outra fisionomia que não duas pernas? Como reconhecer outra forma de comunicação que não a fala? Nossas inquietações passam a perceber o espaço escolar em busca de definir uma estratégia, uma organização, uma prova, em que esteticamente $^{13}$ caibam todos, mas que na profundidade ferem a existência da diferença. Nesse cenário, a escola sinaliza a necessidade de normalização, medicalização e reabilitação a que frequentemente os alunos com alguma 'marca' de diferença são submetidos. A diferença passa a sobreviver à vigilância da escola, aos seus olhares duvidosos e julgadores que pretendem decifrá-la, enquadrá-la, dominá-la. Inquietam-

13 Skliar (2003) problematiza o interesse da escola em parecer esteticamente inclusiva, sendo que o processo de inclusão, muitas vezes, pedagogicamente não se efetiva. 
nos os sinais de que muitas vezes a escola demonstra apenas preocupação com a estética de sua hospedagem ${ }^{14}$ e pouco com os seus sujeitos. Em outras palavras:

(...) o conceito de diferença parece estar atrelado a uma ideia de dificuldade/de falta, já que fugiriam de uma norma pré-estabelecida configurada através das maiorias. As minorias que por diversas razões venham a fugir deste padrão, correm um grande risco de permanecerem à margem do lugar a que pertencem/ou possuem o direito de pertencer (SCHWENGBER; UHMANN; MEDEIROS, 2015, p. 217).

O contexto da Educação de Surdos - lugar para constantemente problematizar ${ }^{15}$ traz a necessidade de 'ir aos porões' de Veiga-Neto (2012, p.269), uma vez que “adentrar nesse lugar e escrutiná-lo o mais cuidadosa e intensamente possível, pois, apesar de escuro, ele guarda os arquétipos que, sem sabermos que são construções contingentes, tomamos como verdades necessárias". Estas ideias possibilitam refletir sobre a diferença surda ${ }^{16}$, as quais vão além da diversidade ${ }^{17}$, enaltecendo a possibilidade da diferença linguística e cultural dos surdos. A perspectiva da diferença é aqui entendida como a existência do diverso, do devir, do múltiplo, que está sempre em ação, se produz, prolifera e se recusa a fundir-se no estático, no dado, na diversidade $\operatorname{programada}^{18}$. Porém, os discursos da surdez como diferença política, linguística e cultural nem sempre predominam na escola. Skliar (1998, p. 11) explica que:

As diferentes representações da surdez (...) podem ser descritas do seguinte modo: a surdez constitui uma diferença a ser politicamente reconhecida; a surdez é uma experiência visual; a surdez é uma identidade múltipla ou multifacetada e, finalmente, a surdez está localizada dentro do discurso sobre a deficiência.

${ }^{14}$ Skliar (2003) pergunta: trata-se, talvez, de um eu que, simplesmente, se dispõe a hospedar, e/ou se inquieta pela própria estética de sua hospedagem (hostil?)? Nós perguntamos: trata-se de uma escola que simplesmente aceita (hospeda) a diferença, ou que apenas se vislumbra com sua própria aceitação (estética da hospedagem)?

1530 Problematizar é entendido segundo a perspectiva de Miller e Rose (2012, p. 210): “uma maneira pela qual a experiência chega a ser organizada de modo a transformar algo em um problema". Condiz, também, com o que Foucault pensava: "a elaboração de um dado em questão, a transformação de um conjunto de complicações e dificuldades em problema para os quais as diversas soluções tentarão trazer uma resposta. [...] a problematização como um trabalho do pensamento" (FOUCAULT, 2002, p. 233).

${ }^{16}$ Estas reflexões utilizam "diferença surda" como uma definição positiva ao referir-se à diferença dos surdos diante de sua perspectiva linguística e cultural, entre outras, que pode ser considerada sempre multifacetada e plural.

17 A diversidade ocorre por meio de mecanismos e instituições que fixam determinadas identidades, ordenadas e organizadas conforme estabelecimento de algumas regras. Por isso, a diversidade não é, nunca, um ponto de origem: ela é, em vez disso, o ponto final de um processo conduzido por operações de diferenciação (SILVA, 2000).

${ }^{18} \mathrm{Na}$ perspectiva da diversidade, a diferença tende a ser naturalizada, cristalizada, essencializada em uma explicação ou poucos modos de ser e existir. 
As muitas representações da surdez descritas acima reforçam a existente perspectiva da diferença, estando sobre esta última representação citada pelo autor acima, ainda "localizada dentro do discurso sobre a deficiência", nossas preocupações, pois de antemão é uma representação limitada, bem como pode servir de justificativa para que a escola use de suas estratégias normalizadoras. Ora, se a surdez é contemplada na deficiência, nada mais "esperado" do que sobre ela se estabeleçam estratégias de correção e reabilitação.

Ao que parece, mesmo em tempos de Educação Inclusiva, ainda vivenciamos abismos: normais versus diferentes, deficientes versus não deficientes, ouvintes versus surdos; esse contexto muitas vezes aponta a tentativa visível de minimizar as marcas da diferença e, se possível, "caridosamente” enquadrar nos espaços descritos e predefinidos da diversidade aqueles que as apresentam. Ao que se sabe, no estabelecimento desses binarismos, é como se as identidades do centro (estabelecidas por meio de uma norma ${ }^{19}$ ) buscassem empurrar a diferença para as margens, estrategicamente organizadas para recebê-las, sem lhes conceder possibilidade de escolha quanto à sua permanência. Olhar para esse movimento reafirma os discursos que por muito tempo prevaleceram sobre os surdos, em um modelo de medicalização da surdez, com tentativas incessantes de recorrer a mecanismos de correção, regulação, normalização e segregação a partir da pedagogia - demarcando o quanto estar próximo ou representar a diferença ainda pode conferir, a partir de um olhar ouvintista ${ }^{20}$, lugares excluídos e segregados a esses sujeitos (SKLIAR, 2003), ou ainda a exigência da aprendizagem de uma língua e cultura que não são os seus.

Há espaço para a produção de olhares de estranhamento sob os alunos surdos, uma vez que, por exemplo, eles necessitam de outra forma de comunicação, que não a da maioria ouvinte. Trata-se da presença de uma comunicação 'não tradicional' que, de forma visível, pertence "apenas" aos sujeitos surdos. Há aqui um campo teórico que apresenta a diferença surda - nem sempre entendida de forma positiva, mas historicamente questionada pela maioria ouvinte - constituindo barreiras na

\footnotetext{
${ }^{19}$ Vale lembrar que a norma estabelece uma proximidade com a normalidade ocidental, cristã, branca, heterossexual, burguesa, física e intelectualmente "normal" (SKLIAR, 2003)

${ }^{20}$ Segundo Skliar (2013, p. 15), "trata-se de um conjunto de representações dos ouvintes, a partir do qual o surdo está obrigado olhar-se e a narrar-se como se fosse ouvinte".
} 
comunicação e sendo responsável pelo hiato existente entre surdos e ouvintes (QUADROS, 2003). Observar o cenário educacional que diversas vezes se apresenta discursivamente como escolas de ouvintes em que se "aceitam" alunos surdos incluídos é situar-se no limiar de um terreno pantanoso que ainda não se tem certeza sobre os caminhos a percorrer. Se, de um lado, há um movimento de inclusão em escolas regulares, com propostas de Atendimento Educacional Especializado (AEE) e tentativas de interação entre surdos e ouvintes, de outro, algumas vezes há a preferência dos próprios surdos pela permanência nas escolas especiais, pois ainda pouco entendem efetivadas as possibilidades de inclusão dos surdos na escola regular.

Os caminhos que perpassam a escolarização dos alunos surdos podem exibir muitas sinalizações. Sinalizações que apresentam estratégias corretivas, práticas disciplinares e tentativas de normalização, sob a ótica da gerência de risco ${ }^{21} \operatorname{como}$ uma medida da racionalidade política neoliberal ${ }^{22}$, implicada na configuração e operacionalização da Educação Especial na proposta de inclusão na escola regular. Por outro lado, 'entram em cena' ideias que buscam o reconhecimento da surdez como diferença linguística, afastada da representação biológica, do déficit, da perda, e entendida a partir da comunicação visual, que se constitui, entre outros aspectos, na legitimidade da utilização da língua de sinais.

Contudo, o que parece estar em jogo não é apenas o local de escolarização (regular ou especial), mas o acesso e permanência oportunizados aos alunos surdos na escola. Tratam-se de vivências escolares que importam ser problematizadas pois, segundo Larrosa (2011, p. 5), a 'experiência' não é um simples acontecimento, como um experimento, mas aquilo "que me passa, [...] que não depende de mim, [...] nem das minhas ideias, $[\ldots]$ nem das minhas intenções $[\ldots]$ :

Mas, supõe [...] algo que me passa. Não que passa ante mim, ou frente a mim, mas a mim, quer dizer, em mim. A experiência supõe um acontecimento exterior a mim. Mas, o lugar da experiência sou eu. É em mim (ou em minhas palavras, ou em minhas ideias, ou em minhas representações, ou em meus

${ }^{21}$ Gerência de risco entendida aqui como estratégias possíveis para conter o que historicamente foi entendido como risco: a deficiência (SKLIAR, 2003).

22 Detém-se sobre a racionalidade governamental do Estado, ou seja, a arte de governar além da questão econômica, o que abrange e quer controlar os próprios sujeitos e seus comportamentos a partir de diferentes estratégias. Os sujeitos de direito aparecem como uma população que interesse administrar e gerir (FOUCAULT, 1979). 
sentimentos, ou em meus projetos, ou em minhas intenções, ou em meu saber, ou em meu poder, ou em minha vontade) onde se dá a experiência, onde a experiência tem lugar (LARROSA, 2011, p. 5-6).

Estas vivências (ou, para Larrosa, experiências) subjetivam os sujeitos de acordo, entre outras questões, com as condições de acesso e a permanência no espaço escolar. Se levarmos em consideração as pesquisas aqui já destacadas - a exemplo: Silva (2015), Morais (2015) e Schubert (2017) - a inclusão de alunos surdos pode ser problematizada através dos conceitos de exclusão e normalização. Sobre exclusão, vale refletir a 'estranheza' com que a escola muitas vezes ainda considera e demarca a diferença, sobretudo a diferença surda. Por vezes é possível entender a inclusão 'revestida' de exclusão (SKLIAR, 2003) a posicionar alunos por meio de práticas pedagógicas que pouco consideram a surdez, mas preocupam-se em manter verdades hegemônicas que continuam a posicionar os surdos em lugares não privilegiados na escola, mantendo vivências segregadas ou apenas integrada aos demais considerados "normais". Incluir o surdo ou mesmo a Língua de Sinais pode ser um movimento narcísico quando se faz não pelo outro, mas como uma forma de mostrar a tolerância da língua que 'eles não falam' ou do que 'eles não são'.

Sobre normalização, é possível destacar o quanto estratégias (aos surdos: conseguir oralizar, frequentar o Atendimento Educacional Especializado, entre outros) possuem impacto na permanência dos surdos nos espaços escolares e produzem/possibilitam suas subjetividades. Ou seja, a escola tem a possibilidade de promover um espaço normalizador, estimulando, por exemplo, saberes médicos ou práticas pedagógicas investidas de reabilitação. Nisso, a perspectiva bilíngue também pode ser observada, mas outras abordagens educacionais orais muitas vezes acontecem simultaneamente na escola e são por ela valorizadas. É como se a escola não incluísse o outro pelo outro, mas o observasse com os espelhos da mesmice e buscasse refletir o que dela é esperado (diz ser bilingue, mas permanece central a oralidade).

Entretanto, se por um lado a inclusão de alunos surdos pode apresentar vivências de exclusão e/ou normalização, por outro, podem impulsionar o reconhecimento de resistência às imposições ainda ouvintistas no espaço escolar e/ou legitimação da diferença como importantes para a qualificação da escolarização de alunos surdos. 
Sobre resistência, é possível reconhecer o surdo não mais expressamente fixo ao assujeitamento, mas também com possibilidade de refletir sobre si, sua história, desafiar sua realidade e propor modificações, sobretudo diante das lutas políticas que ativamente são travadas pela comunidade surda. Há espaço para a existência de um outro modo de subjetivação, sinalizante e visual, nem melhor nem pior, mas diferente de ser. Assim:

\begin{abstract}
Quebrar o paradigma da deficiência é enxergar as restrições de ambos: surdos e ouvintes. Por exemplo, enquanto um surdo não conversa no escuro, o ouvinte não conversa debaixo d'água, em local barulhento, o ouvinte não consegue se comunicar, a menos que grite e, nesse caso, o surdo se comunica sem problemas. Além disso, o ouvinte não consegue comer e falar ao mesmo tempo, educadamente, enquanto o surdo não sofre essa restrição. Se consideramos que os surdos não são 'ouvintes com defeito', mas pessoas diferentes, estaremos aptos a entender que a diferença entre pessoas surdas e pessoas ouvintes gera uma visão não-limitada, não-determinística de uma pessoa ou de outra, mas uma visão diferente de mundo, um 'jeito Ouvinte de ser' e um 'jeito Surdo de ser', que nos permite falar numa cultura de visão e noutra da audição (SALLES, 2004, p. 38).
\end{abstract}

Culturas, no plural, que possam compartilhar ideias, buscar aproximações ou discordar, sem que isso seja motivo para a exclusão/segregação/distanciamento de uma ou outra. Quando podemos pensar no acesso e permanência de alunos surdos na escola regular segundo essas ideias, podemos, também, pensar na alteração de ideias limitadoras às ideias repletas de possibilidades. Possibilidades que legitimam a existência da diferença e as estimulam a permanecer. Aos surdos, nada mais do que um direito previsto legalmente, mas que nem sempre é a eles legitimado.

As possibilidades para a escolarização de alunos surdos trazem o reconhecimento de sua cultura, identidade, língua, como um novo caminho a ser firmado para a efetivação de sua inclusão. Perdem força discursos médicos, bem como contestam-se reflexões que ainda tragam resquícios do anterior. O que se quer é valorizar a diferença dos surdos, reconhecê-la como legítima a ser considerada e respeitada nos espaços escolares, sem fixar sua identidade, já que segundo Silva (2000, p. 9):

Legitimar a diferença não pode significar "deixar que o outro seja como eu sou" ou "deixar que o outro seja diferente de mim tal como eu sou diferente (do outro)", mas deixar que o outro seja como eu não sou, deixar que ele seja esse outro que não pode ser eu, que eu não posso ser, que não pode ser um (outro) eu; significa deixar que o outro seja diferente, deixar ser uma diferença que não seja, em absoluto, diferença entre duas identidades, mas diferença da identidade, deixar ser uma outridade que não é outra 
"relativamente a mim" ou "relativamente ao mesmo", mas que é absolutamente diferente, sem relação alguma com a identidade ou com a mesmidade.

O caminho? Refletir a importância do encontro com o Outro, com o Outro surdo, com a diferença surda, sem o intuito de modificar, excluir, segregar. Para Rigo (2018, p. 15-16), "faz-se necessário o tempo da experiência, o tempo de o professor viver com cada aluno a experiência de ensinar a quem possui condições adversas àquelas dos demais”. A partir do 'encontro' com a diferença surda, formas de entender esses sujeitos podem modificar e, por sua vez, tencionar os efeitos de exclusão e/ou normalização produzidos na/pela escola. Tratam-se de encontros capazes de descontruir os modos de representação colonizadoras que temos sobre o 'Outro surdo'. "Somente subjetividades abertas ao outro podem deixar-se afetar pelo outro, porque estas estariam destituídas da supremacia do Eu, vulneráveis diante do outro, produzindo acolhimento e responsabilidade do Eu pelo Outro" (RIGO, 2018, p.16). No ‘encontro com o outro’ há o encontro com a alteridade que (re)constrói as subjetividades "não mais a partir do Eu, mas pela estrutura um-para-o-outro, na qual a subjetividade é descrita nos termos de acolhimento e responsabilidade (MIRANDA, 2014, p. 468) de que cada um é 'um' e importante para 'o todos'.

\section{IDEIAS E PROBLEMATIZAÇÕES FINAIS}

A escolarização de alunos surdos ao longo dos anos - mais precisamente por meio de pesquisas recentes como as de Lopes (2017) e Vieira (2017) - possibilitam perceber o quanto esta modificou-se para atender ao que reconhecemos atualmente como Educação Bilingue. Se, por um tempo, a escolarização de alunos surdos foi pautada apenas por saberes hegemônicos e sobrepostos a discursos de normalização e reabilitação, agora pode ser compreendida mediante outras sinalizações, especialmente na perspectiva da diferença linguística dos surdos.

A Educação Bilingue vem como possibilidade de reconhecimento e legitimação da diferença dos surdos, possibilitando a estes sujeitos primeiramente o acesso e respeito à Língua de Sinais Brasileira (considerada sua língua natural e materna) e, como segunda língua o Português escrito. Não há mais espaço para 'o surdo com 
defeito' ou 'o surdo que precisa aprender a falar'. Tais mudanças fazem considerar o processo de evolução e de lutas no campo dos direitos humanos e comunidade surda, em que podemos encarar o surdo como autor e ator de uma cultura minoritária (SÁ, 2002) - não havendo uma ou outra cultura, mas culturas, na pluralidade à subjetivar-se de formas diferentes e singulares.

No entanto, não podemos nos deixar 'adormecer' e entender que estas são questões finalizadas. Na educação de surdos, o acesso e permanência desses alunos nos espaços escolares é discursivamente pautado por meio do respeito ao uso e valorização da língua de sinais na escola, a garantia de interações entre surdos-ouvintes, formação de professores, dentre outros - aspectos nem sempre vivenciados nas realidades escolares. Todos estes, justificados em ideais de uma sociedade mais democrática e 'para todos' e, respaldados em textos e materiais produzidos pelo Ministério de Educação (MEC), por exemplo, que apontam estratégias 'convidativas': “incentivo à oficialização da LIBRAS”; "alternativas diferenciadas para a comunicação entre os portadores de deficiência auditiva, por exemplo, legendas nas programações de TV e de intérprete de língua de sinais"; o entendimento de que "a língua de sinais (LS) é a primeira língua do indivíduo surdo e que, através dela, ele constituirá sua identidade e leitura do mundo"; e a alusão à participação dos surdos na definição das questões culturais, econômicas e políticas relacionadas a sua vida - "o surdo, como parte integrante da comunidade escolar, deve participar das decisões políticas que dizem respeito ao seu processo educacional"23.

Tratam-se de disposições 'sedutoras' que demonstram estar preocupadas com o acesso de alunos surdos à inclusão, bem como respaldadas legalmente pela estética da promoção ao direito de todos à educação - não havendo mais espaço para discursos que neguem este fato. Contudo, o que precisa ser constante motivo de problematizações é a permanência nas escolas e, sobretudo, com qualidade, já que o aumento crescente do número de matrículas de alunos surdos no sistema regular de ensino não garante uma permanência que realmente contribua com a aprendizagem e desenvolvimento desses alunos. A escola é espaço que a todo o momento possibilita subjetivações e por isso 
precisamos estar atentos sobre o que ela sinaliza como condições não apenas de acesso, mas também da permanência desses alunos na inclusão escolar. Enfim, quais são as subjetivações que estão nesses espaços sendo possíveis?

Que o caminho possa ser constante e contínuo no entendimento de que a cultura, língua, diferença dos surdos são tão legítimas e importantes como a dos ouvintes. Estas reflexões nos levam a entender a inclusão acontecendo tão somente quando os surdos forem reconhecidos na/pela sua diferença, sendo possível a eles existirem sem a solicitação de quaisquer mudanças. Isto será consequência quando o acesso e a permanência desses alunos forem possibilitados segundo suas singularidades.

\section{REFERÊNCIAS}

ABREU, Márcia Cristina Barreto Fernandes de. A constituição de surdos em alunos no contexto escolar: conflitos, contradições e exclusões. Tese de Doutorado. Programa de Pós-Graduação da Universidade Federal de Uberlândia. 2016.

AMORIM, Lucio Cruz Silveira. Políticas educacionais de inclusão: a escolarização de surdos em Uberlândia/MG. Dissertação de Mestrado. Programa de Pós-Graduação em Educação da Universidade Federal de Uberlândia. 2015.

ANASTASIOU, Léia das Graças Camargo; ALVES, Leonir Passate.(orgs.). Processos de ensinagem na universidade: pressupostos para as estratégias de trabalho em sala de aula. 6 Ed. - Joinville, SC: UNIVILLE, 2006.

ANGELUCCI, Carla. \& LUZ, Renato. Contribuições da escola para a (de)formação dos sujeitos surdos. Psicologia Escolar e Educacional, vol. 14(1), p.35-44, 2010.

\section{BRASIL. Presidência da República. Política nacional de educação especial na} perspectiva da educação inclusiva. Brasília, 2008.

CACERES, Marcele Martinez. Possíveis negociações dos discursos curriculares no contexto da educação bilíngue de uma escola de surdos do Rio Grande do Sul.

Dissertação de Mestrado. Programa de Pós-Graduação em Educação da Universidade Federal de Santa Maria. 2016.

CARNEIRO, Fernando Henrique Fogaça. O ensino da matemática para alunos surdos bilíngues: uma análise a partir das teorizações de Michel Foucault e Ludwig Wittgenstein. Dissertação de Mestrado. Programa de Pós-Graduação em Educação da Universidade Federal do Rio Grande do Sul. 2017. 
CASTRO, Edgardo Manuel. Vocabulário de Foucault: Um percurso pelos seus temas, conceitos e autores. Belo Horizonte: Autêntica, 2009.

CEZIMBRA-CONRADO, Juliana. As artes do governar do contexto da educação de surdos: estratégias de governamento na escola inclusiva. Dissertação de Mestrado. Programa de Pós-Graduação em Educação da Universidade Federal de Santa Maria. 2014.

COSTA, Juliana Pêgas. A prática docente na inclusão educacional de um aluno surdo com implante coclear. Dissertação de Mestrado. Programa de Pós-Graduação em Educação da Faculdade de Educação da Universidade Federal do Rio de Janeiro. 2015.

DRUMOND, Andréa Hees. Escola bilíngue para surdos: constituição de práticas que configuram um espaço bilíngue. Dissertação de Mestrado. Programa de PósGraduação do Centro de Educação da Universidade Federal do Espírito Santo. 2017.

FILHO, Pedro Luis dos Santos. Escolarização de Surdos no Ensino Médio em Natal/RN: vendo e ouvindo vozes. Dissertação de Mestrado. Programa de PósGraduação em Educação do Centro de Educação da Universidade Federal do Rio Grande do Norte. 2015.

FOUCAULT, Michel. Os anormais: curso no Collège de France (1974-1975). São Paulo: Martins Fontes, 2002.

FOUCAULT, Michel. Microfísica do Poder. Organização, introdução e revisão técnica de Roberto Machado. 20 ed. Rio de Janeiro: Edições Graaal, 1979.

JUNIOR, Ademar Miller. A inclusão do aluno surdo no ensino médio. Dissertação de Mestrado. Programa de Pós-Graduação em Educação, do Centro de Educação, da Universidade Federal do Espírito Santo. 2013.

LACERDA, Cristina Broglia Feitosa de. A inclusão escolar de alunos surdos: o que dizem alunos, professores e intérpretes sobre esta experiência. Caderno Cedes. vol. 26(69), p. 163184, 2006.

LARROSA, Jorge. Experiência e alteridade em educação. Revista Reflexão e Ação, Santa Cruz do Sul, v.19, n. 2, p. 04-27, jul./dez. 2011.

LOPES, Luciane Bresciani. Emergência dos estudos surdos em educação no Brasil. Dissertação de Mestrado. Programa de Pós-Graduação da Universidade Federal do Rio Grande do Sul. 2017.

LOSS, Jaqueline Reni. Percursos de escolarização de acadêmicos surdos no ensino superior. Dissertação de Mestrado. Programa de Pós-Graduação da Universidade Comunitária da Região de Chapecó. 2015. 
LUCHESE, Anderson. Formação docente para a atuação com estudantes surdos.

Dissertação de Mestrado. Programa de Pós-Graduação em Educação da Universidade Comunitária da Região de Chapecó. 2016.

LÜDKE, Menga e ANDRÉ, Marli E. D. A. Pesquisa em educação: abordagens qualitativas. São Paulo: EPU, 1986.

MAROSTEGA, Vera Lúcia. Os currículos de formação de professores para surdos na UFSM: Educação Especial como campo de Saber. Tese de doutorado. Programa de Pós-Graduação em Educação da Universidade do Vale do Rio dos Sinos. 2015.

MARTINS, Vanessa Regina de Oliveira. O que me torna invisível? A psicanálise como ferramenta para entender o "apagamento" das diferenças na inclusão escolar de surdos. Revista ETD - Educação Temática Digital, Campinas, v.8, n.esp., p.135-152, dez. 2006.

MARTINS, Cássia Lobato. Processos de construção e desenvolvimento de currículos para surdos com deficiência em uma escola bilíngue para surdos. Dissertação de mestrado. Programa de Pós-Graduação em Educação da Universidade Federal do Rio Grande do Sul. 2015.

MATIAS, Wander Luís. Surdos "incluídos": sujeitos ou assujeitados? Dissertação de Mestrado. Programa de Pós-Graduação da universidade Federal de Uberlândia. 2015.

MILLER, Peter; ROSE, Nikolas. Governando o presente: gerenciamento da vida econômica, social e pessoal. São Paulo Paulus: 2012.

MIRANDA, J. V. A. Lévinas e a reconstrução da subjetividade ética: aproximações com o campo da educação. Revista Brasileira de Educação, Rio de Janeiro, v. 19, n. 57, abr./jun., p. 465-475, 2014.

MORAIS, Mônica Zavacki de.A emergência das políticas de educação bilíngue para surdos no brasil na racionalidade inclusiva. Tese de Doutorado. Programa de PósGraduação em Educação da Universidade Federal de Santa Maria. 2015.

PATROCÍNIO, Paulo Roberto Tonani. Estudos culturais, diferença e surdez: uma leitura teórica. Revista Periferia: educação, cultura e comunicação. v.9 n.1 jan-jun, 2017. Pp. 130-153.

QUADROS, Ronice Muller de. Situando as diferenças implicadas na educação de surdos: Inclusão/exclusão. Ponto de Vista, vol. 05, p. 81-111, 2003.

RIBEIRO, Maria Clara Maciel de Araújo; LARA, Glaucia Muniz Proença. O Eu e o Outro no campo discursivo da surdez. Revista Estudos Semióticos/USP, v. 6, n.2, p. $55-65,2010$. 
RIGO, Neusete Machado. O dispositivo da Inclusão Escolar e a Produção de Subjetividades. Vol. 1, n. 3. Set./Dez. 2018. Revista Insignare Scientia (RIS). p. 1-24.

SÁ, Nídia Regina Limeira de. Cultura, poder e educação de surdos. Manaus: Editora da Universidade Federal do Amazonas, 2002.

SALLES, Heloísa Maria Moreira Lima (et al). Ensino de língua portuguesa para surdos: caminhos para a prática pedagógica. Brasília: MEC, SEESP, 2004.

SAMPAIO, Carmen Sanches. A presença de uma aluna surda em uma turma de ouvintes - possibilidades de (re)pensar a mesmidade e a diferença no cotidiano escolar. Revista ETD - Educação Temática Digital, Campinas, v.7, n.2, p.47-57, jun. 2006.

SCHUBERT, Silvana Elisa de Morais. Limites e possibilidades da educação bilíngue para surdos no contexto das políticas de inclusão (1990- 2017): implicações à formação de professores. Tese de Doutorado. Programa de Pós-Graduação em Educação da Universidade Tuiuti do Paraná. 2017.

SCHWENGBER, Maria Simone Vione; UHMANN, Silvana Matos; MEDEIROS, Daniela. Corpos marcados pela deficiência O 'fora do lugar' de muitos alunos. Revista Retratos da Escola, Brasília, v. 9, n. 16, p. 213-226, jan./jun. 2015.

SILVA, Tomaz Tadeu da. Identidade e Diferença: Impertinências. In: Revista Educação \& Sociedade, ano XXIII, nº. 79, Agosto. 2002.

SILVA, Tomaz Tadeu da. A produção social da identidade e da diferença. In: SILVA, Tomaz Tadeu da (org. e trad.). Identidade e diferença: a perspectiva dos estudos culturais. Petrópolis: Vozes, 2000. p. 73-102.

SILVA, Adriana Ramos. O desafio do bilinguismo para alunos surdos no contexto da inclusão: o caso de uma escola municipal do Rio de Janeiro. Dissertação de Mestrado. Programa de Pós-Graduação da Faculdade de Educação da Universidade Federal do Rio de Janeiro. 2015.

SKLIAR, Carlos. A educação para surdos entre a pedagogia especial e as políticas para as diferenças: desafios e possibilidades na educação bilíngue para surdos. Rio de Janeiro: Instituto Nacional de Educação de Surdos, 1998.

SKLIAR, Carlos. Pedagogia improvável da diferença: e se o outro não estivesse aí? Rio de Janeiro: DP\&A, 2003.

SKLIAR, Carlos. A surdez: um olhar sobre a diferença. Porto Alegre: Mediação, 2013. 6 ed.

STÜRMER, Ingrid Ertel. Educação bilíngue: discursos que produzem a educação de surdos no Brasil. Dissertação de Mestrado. Programa de Pós-Graduação em Educação da Universidade Federal do Rio Grande do Sul. 2015. 
UHMANN, Silvana Matos. Alunos com deficiência: inclusão, desafios, interações e possibilidades. Curitiba: Appris, 2018.

VARELA, Julia. \& ALVAREZ-URIA, Fernando. A Maquinaria escolar. Teoria \& Educação. São Paulo, n. 6, p.68-96, 1992.

VEIGA-NETO, Alfredo. É preciso ir aos porões. Revista Brasileira de Educação. v. 17 n. 50 maio-ago. 2012.

VIEIRA, Claudia Regina. Educação bilíngue para surdos: reflexões a partir de uma experiência pedagógica. Tese de Doutorado. Programa de Pós-Graduação da Faculdade de Educação da Universidade de São Paulo. 2017. 